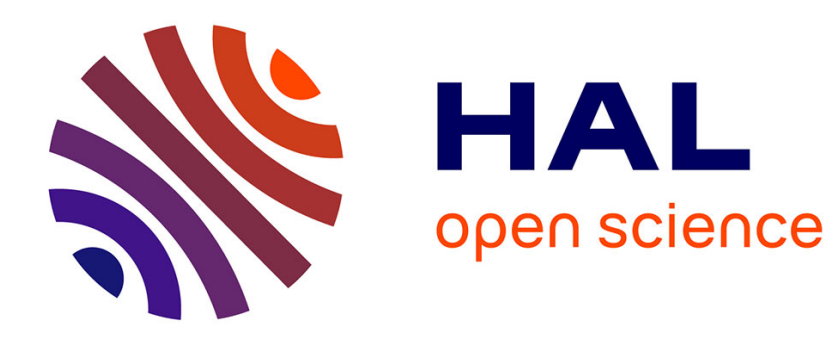

\title{
M.P. belt deterioration. Accelerator structure. Belt capability
}

\author{
M. Letournel
}

\section{To cite this version:}

M. Letournel. M.P. belt deterioration. Accelerator structure. Belt capability. Revue de Physique Appliquée, 1977, 12 (10), pp.1375-1382. 10.1051/rphysap:0197700120100137500 . jpa-00244327

\section{HAL Id: jpa-00244327 https://hal.science/jpa-00244327}

Submitted on 1 Jan 1977

HAL is a multi-disciplinary open access archive for the deposit and dissemination of scientific research documents, whether they are published or not. The documents may come from teaching and research institutions in France or abroad, or from public or private research centers.
L'archive ouverte pluridisciplinaire HAL, est destinée au dépôt et à la diffusion de documents scientifiques de niveau recherche, publiés ou non, émanant des établissements d'enseignement et de recherche français ou étrangers, des laboratoires publics ou privés. 


\title{
M.P. BELT DETERIORATION. ACCELERATOR STRUCTURE. BELT CAPABILITY
}

\author{
M. LETOURNEL \\ Centre de Recherches Nucléaires, Université Louis Pasteur, \\ Strasbourg, France
}

\begin{abstract}
Résumé. - Une explication de la destruction des courroies de M.P. est proposée. Elle tient compte de la contrainte de décharge à laquelle est soumise la courroie suite à la conjugaison d'une part d'une trop grande densité de charge, jointe à la contribution de la tension de la machine, et d'autre part à la configuration géométrique des barres de gradient qui induisent un champ inhomogène et permettent à la courroie d'atteindre des tensions trop élevées non compatibles avec la courbe de Paschen particulière à cet endroit. Cette explication conduit à définir le concept de possibilité de charge pour une courroie. La configuration de champ, critique pour une certaine densité de charge, existe également en d'autres endroits. Différentes solutions simples sont proposées pour remédier à cette trop grande contrainte électrique et permettre aux courroies de M.P. de fonctionner dans des conditions électriques normales.
\end{abstract}

\begin{abstract}
An explanation to the M.P. belt deterioration is proposed. It takes into account the strain of discharge to which the belt is submitted following the combination, first of a too high belt charge density in addition to the machine voltage contribution, second the geometrical configuration of the gradient rods which induces an inhomogeneous field and allows the belt to reach too high voltages not compatible with the particular Paschen curve. This explanation leads to define the concept of belt charge capability. The field configuration critical for a certain charge density also exists in other places. Different simple solutions are proposed to cure this problem and allow the M.P. belt to operate under normal electrical conditions.
\end{abstract}

After many years of running time with a M.P. machine, one fact seems evident and somehow paradoxical, the belt withstands the voltage without deterioration (Fig. 1), but no high charge densities, about $400 \mu \mathrm{A}$ that means $4 \mathrm{nC} / \mathrm{cm}^{2}$ or even less with a reasonable high voltage.

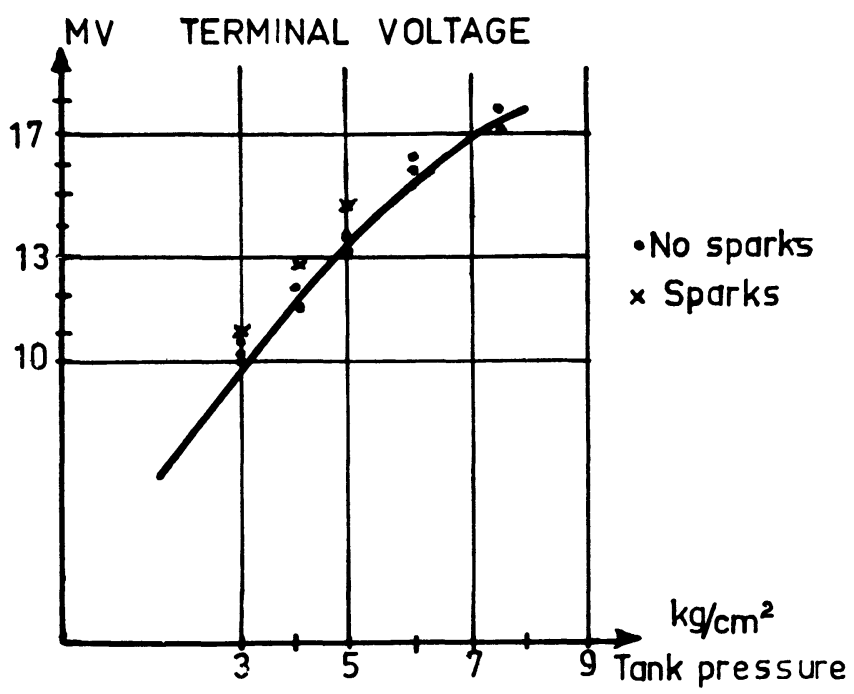

FIG. 1. - Maximum terminal voltage without tubes versus SF6 pressure.
These belt deteriorations seem to have something to do with the control rods and spacers and also with the configuration of the drive motor and its grooves, to let the gas escape (Fig. 2). We know also that there are some reasons to have inhomogeneity in the belt

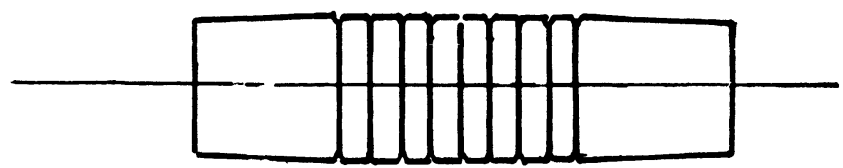

FIG. 2. - Grooves on the drive motor.

charge density [1].

The curve $V$ versus $p$ (Fig. 1) or $V$ versus $p d$ or $V$ versus $d$ are Paschen curves and have all of them the same shape. They can be considered as if coming from an almost uniform field.

Looking at $V$ versus $d$ (Fig. 3 ) it is the same shape in an uniform field, but it becomes ä little more complicated in an inhomogeneous field. For a negative discharge, the curve is lower and roughly uniform, but has a decreasing positive slope with distance. It is not at all the same for a positive discharge where the curve is still lower, and has irregularities. In fact, this is true also for the pressure in an inhomogeneous field. So we get this kind of Paschen curves in an 


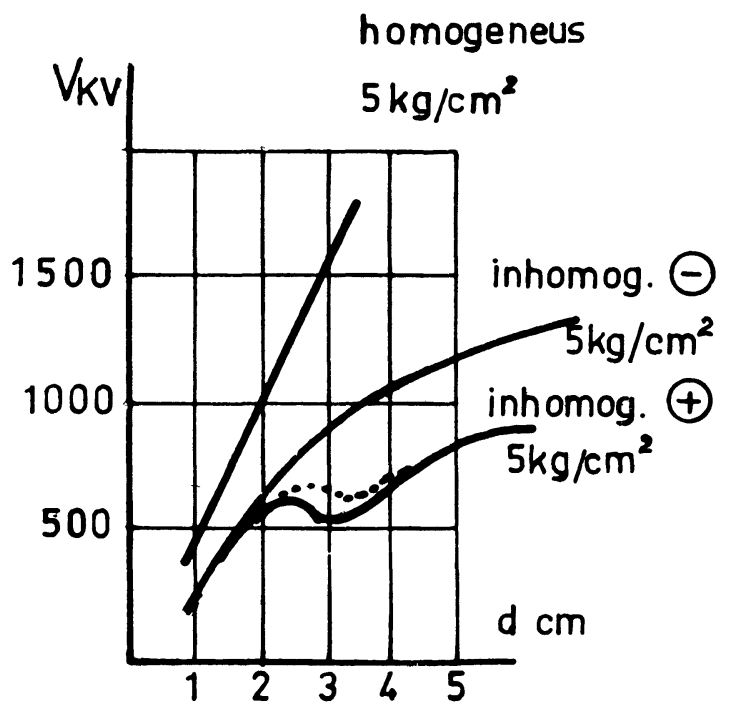

FIG. 3. - Shapes of Paschen curves in SF6 versus distance.

inhomogeneous field, not well determined in a certain area. And with geometrical parameters for the configuration of about $2 \mathrm{~mm} \varnothing$ up to $6 \mathrm{~mm} \varnothing$ which determine the Paschen curve, these disturbances seem to exist around the working pressure 4 or $5 \mathrm{~kg} / \mathrm{cm}^{2}$ for distances of 5 to $15 \mathrm{~mm}$. In fact, the field strength depends on the geometry of the total configuration and very often, modifications in geometric trigger discharge.

When the belt enters the gap between two spacers with a charge density of $4 \mathrm{nC} / \mathrm{cm}^{2}$ the field induced by the belt through this structure is highly inhomogeneous. For example, with data for a rod of $12.5 \mathrm{~mm}$ in diameter, to plane configuration, the breakdown voltage is in the range of $110 \mathrm{kV} / \mathrm{cm}$ (Fig. 4) for $5 \mathrm{~kg} / \mathrm{cm}^{2}$

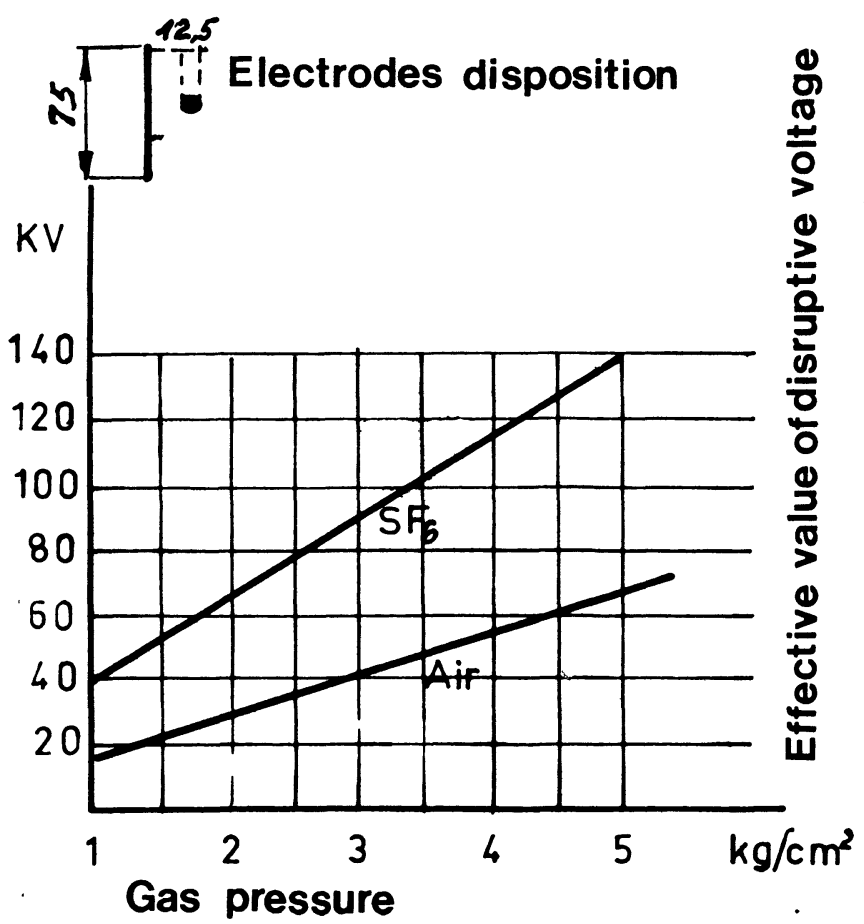

FIG. 4. - Paschen curve versus SF6 pressure in a particular inhomogeneous field configuration.
SF́6 pressure. There is a very divergent configuration of the spacers, with radius of $3 \mathrm{~mm}$ and some more critical points (Fig. 5). $4 \mathrm{nC} / \mathrm{cm}^{2}$ corresponds to

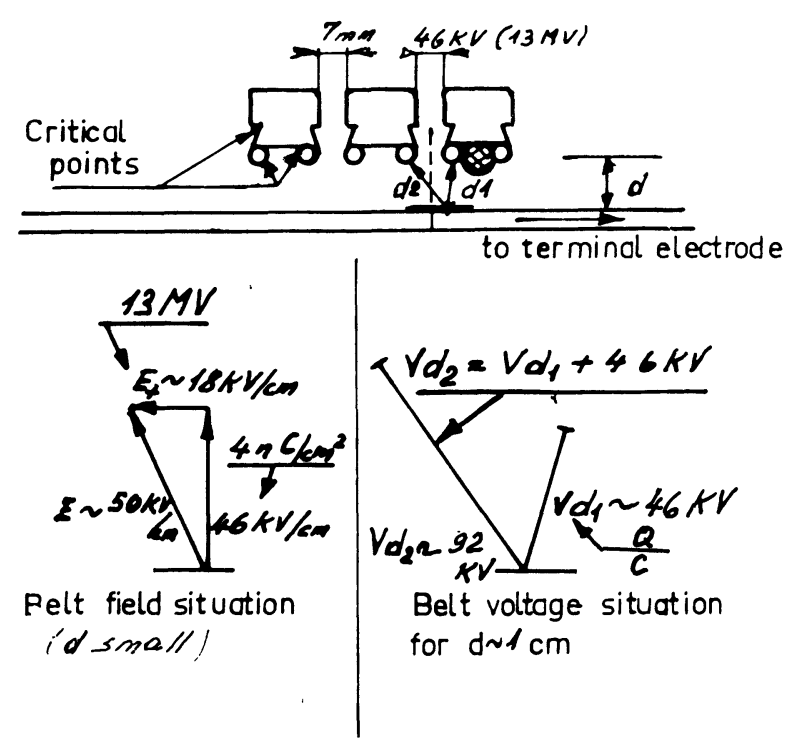
FIG. 5. - Spacers-belt configuration, belt field and belt voltage
situation.

a field of $46 \mathrm{kV} / \mathrm{cm}$ which can be not far from the breakdown limit of the field induced by the belt, close to the critical point, but there is another important factor, about the voltage.

Let us examine first a charged belt in the situation of a half open structure and let us assume that the belt down run is not charged and the influence of the other spacers is negligible. The belt charge density and the geometrical spacer configuration determine an inhomogeneous field, and the Paschen curve varies with the distance. The voltage developped on the charged belt goes up linearly with $d$ (Fig. 6, I). If we increase

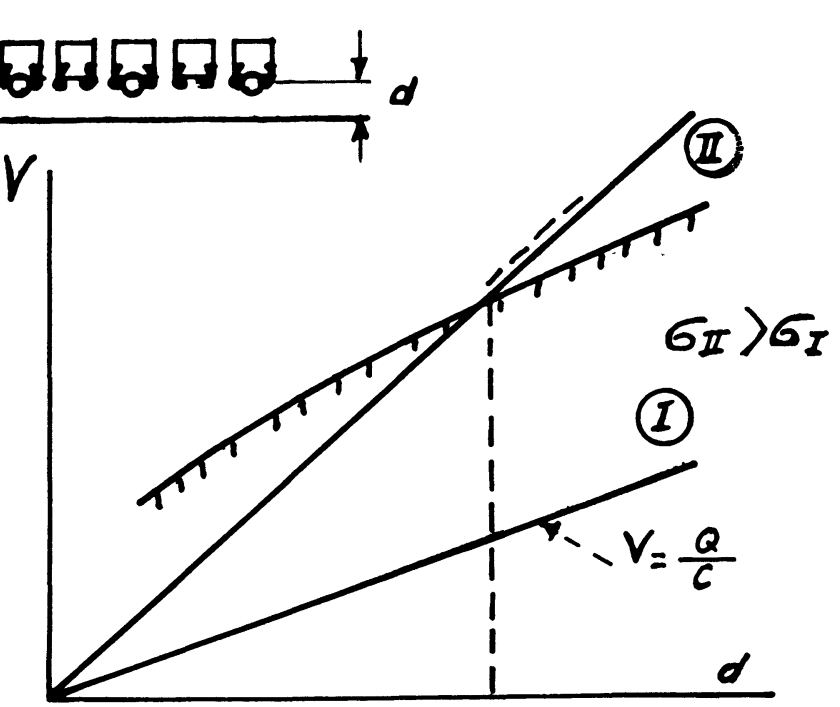

mIrr V Pashen $\longrightarrow$ Belt

FIG. 6. - Belt voltages compared to Paschen curve in half open structure. 
the charge density, that means $Q$, we have another curve II, and there is a certain charge density when the curve II cuts the Paschen curve. At this point we get discharge. Similar processes have been studied by H. Bertein, for charged polymer films in homogeneous field [2]. For a special location of this $\mathrm{cm}^{2}$ (Fig. 5), the same reasoning has to be applied for $d_{1}$ in front of one spacer, but also for $d_{2}$ on the next spacer where the voltage situation becomes more critical. $d_{2}$ has also to be considered because of the relative distances that belt is allowed to have, even in M.P. closed structure. With terminal voltage, spacers or control rods are at different voltages and in fact, discharge can occur from anyone looking at this $\mathrm{cm}^{2}$, the only condition being the voltage difference compared to the Paschen curve.

In the closed H.V.E.C. structure (Fig. 7), the belt is allowed and sometimes obliged by the mechanical setting, to move $3 \mathrm{~cm}$ up and down and it can be

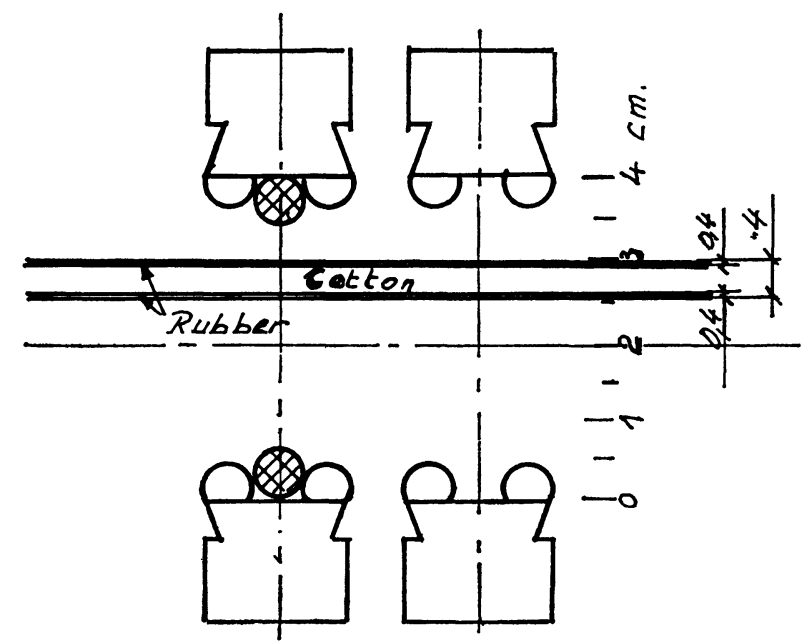

Fig. 7. - H.V.E.C. closed structure.

anywhere in that gap sometimes, along its trajectory. At a same pressure of $5 \mathrm{~kg} / \mathrm{cm}^{2}$ the Paschen curve due to a inhomogeneous structure is not linear with distance. Its maximum is around the middle of the spacers, while when the belt goes from one side to the middle the capacity of the belt itself goes down and the corresponding voltage goes up accordingly. Theoretically $1 \mathrm{~cm}^{2}$ of the top charged surface, right in the middle has a calculated capacity close to $0.1 \mathrm{pF}$ with some simplifications.

Realizing that it is the capacity of $1 \mathrm{~cm}^{2}$ completely insulated and far away from any conductor, in this location, this belt runs as if it were in an almost complete open structure, but worst because in a very inhomogeneous field. It is not surprising at all that, what happens already in a homogeneous field occurs here and that belt voltage induces discharge from the spacers (Fig. 6). In reality, the capacity and its variation are not so drastic and depend strongly of its total environment. But trying to make it clearer, with some-simplifications, let us assume that in this spacer and belt configuration, $1 \mathrm{~cm}^{2}$ of belt top surface, right in the middle, has a calculated capacity considered as a thin conductor plate close to $0.1 \mathrm{pF}$. And that in the $3 \mathrm{~cm}$ gap this calculated capacity can move from $0.3 \mathrm{pF}$ down to $0.1 \mathrm{pF}$ and up to $0.75 \mathrm{pF}$. Governed by the law $Q=C V$ the corresponding belt voltage goes in the reverse way (Fig. 8). The Paschen curve in

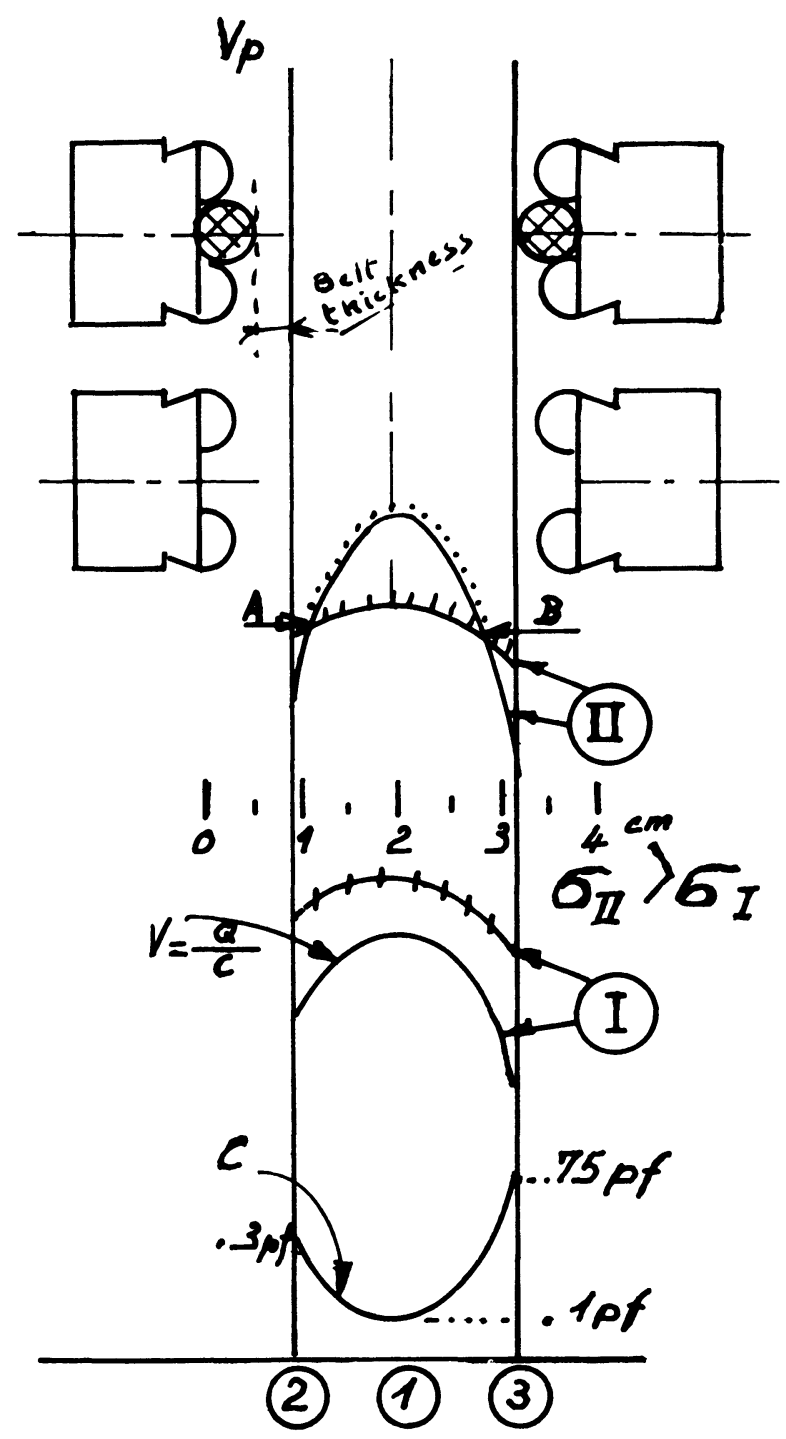

Fig. 8. - Belt voltages compared to Paschen curve in closed structure.

this inhomogeneous field varies also with the distance but is not at all, related as for the other curve which goes up with the charge density. In these positions between $\mathrm{A}$ and $\mathrm{B}$, the belt develops too high a voltage and, in fact, discharge occurs. At the beginning those discharges are not disruptive and drain a very low current. They put a continuous layer of negative charges on the belt. This probably corresponds on the used belts to large areas where the surface is mat because the belt voltage was too high, for many reasons including belt flapping. This causes a small increase of negative current in the return current. As the charge density continues to increase, 
discharges become disruptive in a time of $10^{-8} \mathrm{~s}$ and develop into streamers [2]. Streamers are very harmful and carry a big amount of current. They deposit inhomogeneous and discontinuous charges on the belt that powdering can reveal (Fig. 9). A streamer is a canal formed both with electrons and positive ions going in opposite direction.

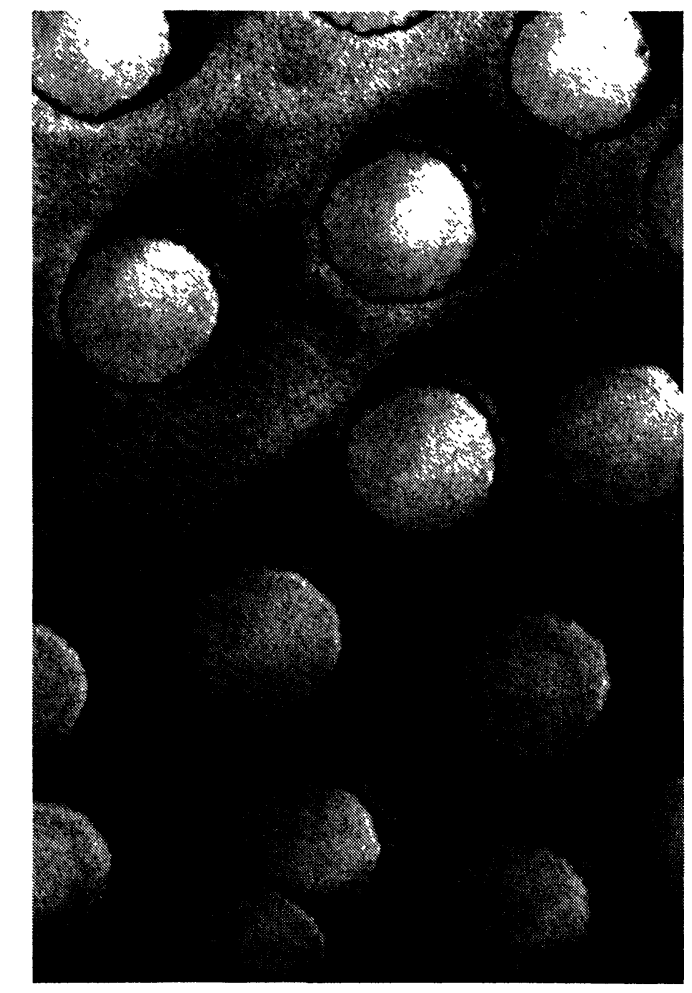

FIG. 9. - Positively charged insulator submitted to an earthed point in SF6. H. Bertein.

Bretonneau $\left({ }^{1}\right)$ reported on an analysis made by the Laboratoire Central des Industries Electriques on a used piece of belt. It is a good illustration and almost a proof of those streamers. The explanation by those streamers induced by the field fits quite well some observations given by Bretonneau and also ours. Around some pin-holes, resistivity measurements on mat areas have revealed some decrease which is a sign of alteration due to the non-disruptive discharge at the beginning of the discharge.

The first microscopic photography (Fig. 10) can be interpreted as following. Coming from above on to the belt there is an electron impact and the middle has a very high temperature. Because of the very high field due to the accumulation of negative charges, gas is ionized and allows the electrons to radiate outwards. The electrons are all together in the nearby and vanish in a circular manner that powdering can materialize. Repetition process brings the complete deterioration of the belt due to the ionized SF6 products and also to

(1) P. Bretonneau, Orsay, Private communication.

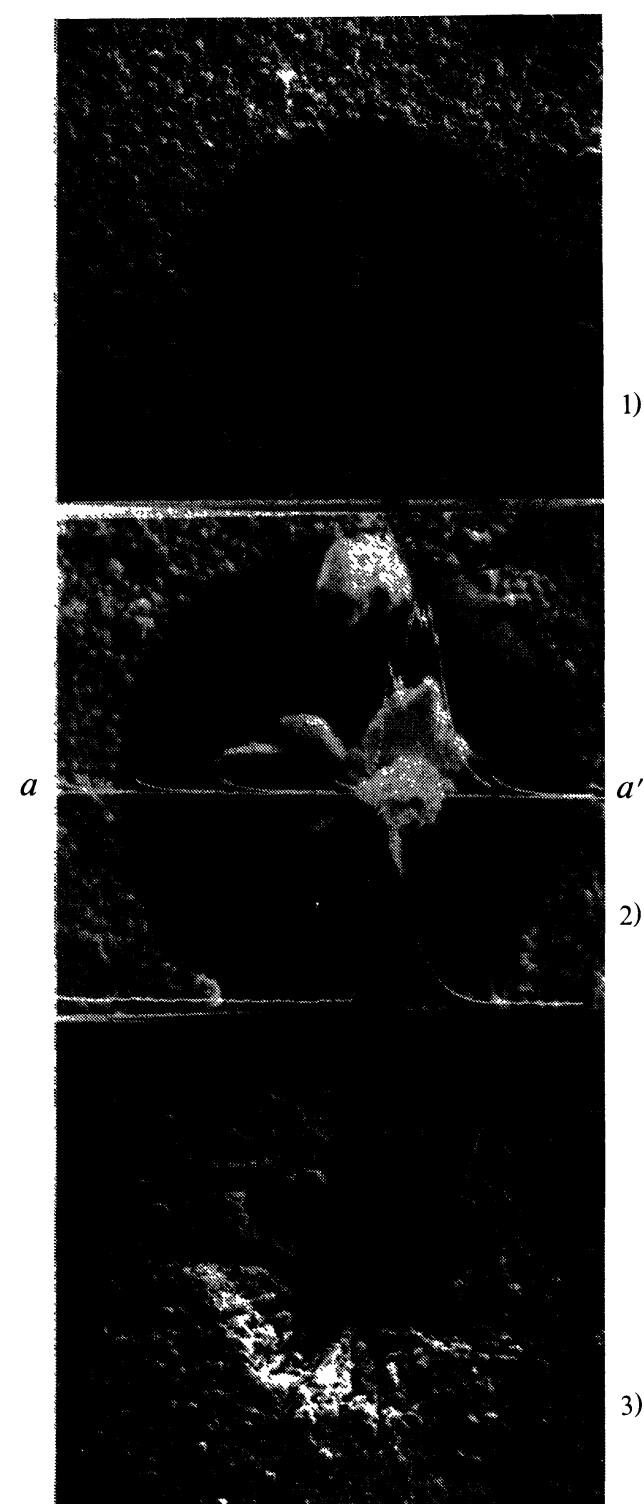

PHOTOGRAPH $\mathrm{n}^{\circ} 1 .-$ Secondary electron image $(\gamma \times 300)$.

Photograph $\mathrm{n}^{\circ} 2$. - Secondary electron image $(\gamma \times 1000)$ $K \alpha \mathrm{Si} \times 10^{2} \mathrm{C} / \mathrm{s}$. $K \alpha \mathrm{Ca} \times 10^{3} \mathrm{C} / \mathrm{s}$.

PHOTOGRAPH $\mathrm{n}^{\circ} 3$. - Secondary electron image $(\gamma \times 140)$.

FIG. 10. - 1) Microscopic photography of a belt round pattern; 2) analysis ; 3) belt pin-hole.

the conductivity of the cotton carcass, the resistivity of which being $10^{9} \Omega \mathrm{cm}$ that means conductive from the electrostatic point of view. On the second photography the analysis of the L.C.I.E. reveals tracks of $\mathrm{Si}$ and $\mathrm{Ca}$ which can may be interpreted as coming with, from spark close to inside the guide near the high alumine ceramic spacer.

To neutralize the charged top surface, electrons discharge can come also from the internal guides and are probably responsible for the pin-holes, that is borne out by the fact that our last ruined belt, which ran without internal guides did not show any pin-hole 
(3rd photography). On the opposite direction considerably slower positive ions reach metallic spacers, and lint, and pieces of cotton are transported onto them (Fig. 11). At this time some increase on the H.E. current can be noticed.

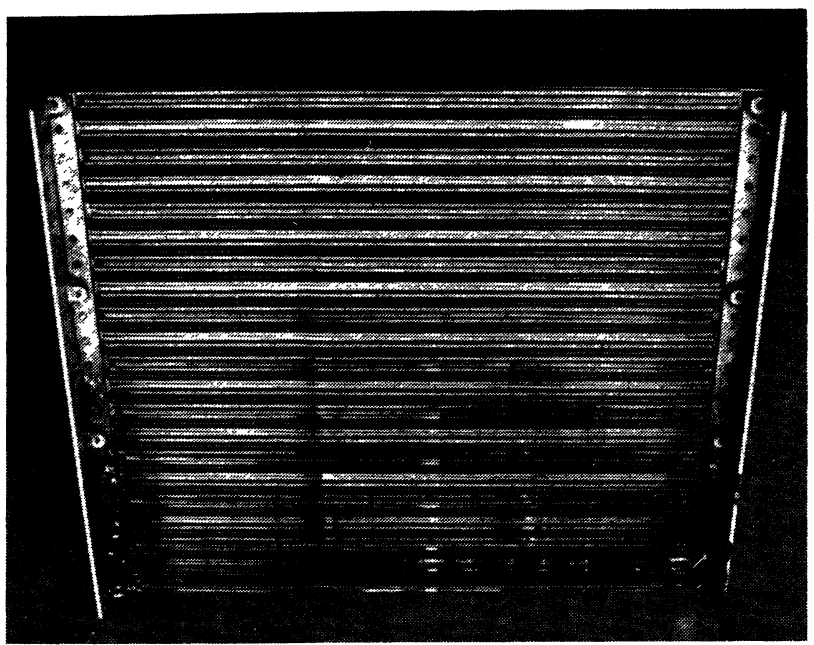

Fig. 11. - Tracks left on the upper spacers and control rods by positive ions coming from the belt.

In case of the down charge this process occurs also in almost a similar manner for the opposite polarity and the electrons going out of the impact leave positive ions on their way and give also circular images. Depending on the sign of the discharge in an inhomogeneous structure I must point out a paradoxical situation occuring with SF6 due to breakdown limit going down when the SF6 pressure is going up (Fig. $3+$ ) the more SF6 pressure we put in the machine to hold the voltage, the more rapidly we can ruin a belt. Discharges and the ionization can cause a certain depolymerisation of the rubber and they have to be avoided since their very beginning.

I come now to the necessity of defining what I would call belt capability as the product $\mathrm{C}=\alpha c$

$c$ has the same value that the capacity $C$ of a thin metallic plate replacing charged surface but with the difference that charges are not allowed to move. $\alpha$ can be defined as the ratio between two corresponding values, one depending on the Paschen curve in the particular inhomogeneous field configuration, including spacers and control rods, and the other depending of the Paschen -curve in an homogeneous field configuration as in open SF6. And coming back to the M.P. spacer, and belt configuration (Fig. 8), I would like to fix this concept which is essential to understand. Let us assume that, $1 \mathrm{~cm}^{2}$ belt top surface, right in the middle, has a calculated belt capacity of $0.1 \mathrm{pF}$ which is close to the theoretical limit far away from any conductor, that means as if it were in a complete - open structure. Let us fix the belt capacities and say that they can move from $0.3 \mathrm{pF}$ down to $0.1 \mathrm{pF}$ and up to $0.75 \mathrm{pF}$, due to belt thickness.
For $5 \mathrm{~kg} / \mathrm{cm}^{2} \mathrm{SF} 6$ pressure in an homogeneous field structure, the charge limit density is ideally $\sigma_{\mathrm{m}}=35 \mathrm{nC} / \mathrm{cm}^{2}$ that means a field $E_{\mathrm{m}}=414 \mathrm{kV} / \mathrm{cm}$ which is very high, just in order to be not limited in our reasoning. In practice the limit density is lower, less than half of that, and lower again for a real gap $(\alpha)$.

If we assume that we have this ideal homogeneous field structure in that gap $(\alpha=1)$ in theory we can consider that, if one $\mathrm{cm}^{2}$ of belt holds $Q \mathrm{nC}$ in position 1 , the same $\mathrm{cm}^{2}$ has a capability of carrying 3 times more charge in position 2 and 7.5 times more in position 3 .

So, if we consider $4 \mathrm{nC} / \mathrm{cm}^{2}$ as a practical common limit of our accelerators in a completely open structure as in position 1 , we are able to have $12 \mathrm{nC} / \mathrm{cm}^{2}$ in position 2 and $30 \mathrm{nC} / \mathrm{cm}^{2}$ in position 3 , all charge densities which are below the theoretical one of $35 \mathrm{nC} / \mathrm{cm}^{2}$.

In another hand, if we put $12 \mathrm{nC}$ on one $\mathrm{cm}^{2}$, in position 2, and if we bring that $\mathrm{cm}^{2}$ in the middle (position 1), we are above the practical $4 \mathrm{nC}$ limit and we will get discharge from position 2 to position 1 because the voltage developed cuts the practical Paschen curve. But if by a mysterious trick we were able to bring that $\mathrm{cm}^{2}$ from position 2 to position 3 without passing through position 1 , we can keep the charge, we are far below the Paschen curve.

Thus carrying charge is determined by the belt capability $C=\alpha c$. In an open structure $\alpha$ can be close to 1 , depending on the field configuration everywhere along the belt trajectory but $c$ is at the utmost $0.1 \mathrm{pF} / \mathrm{cm}$ in the major part of the belt trajectory. So if is impossible to carry more current than something of the order of the limit charge. In a closed structure, $\alpha$ is below 1 and determined by the inhomogeneous field configuration. It varies with the instant belt location. But $c$ can be increased considerably by the metallic proximity in reducing the spacer gap. With this method some ratios compared to an open structure, or limits can be obtained. In practice, it concerns mainly the spacer design and has to be a compromise between $\alpha$ and $c$. In fact, practical measurements similar to Paschen curves measurements can be carried out but they are difficult because of the belt nature. In addition care must be taken for $\alpha$ and $c$ along the complete belt trajectory.

It is essential to understand that it is not the field but the voltages here which determines the discharge, and that it is not the law of the gas rigidity which determines only, there, the structure. Even this law is not so compelling, because from position 3 to position 1 the field decreases. In position 3 the field is turned towards one side and is limited by $E=4 \pi \sigma_{\mathrm{m}}$, it is the law of the gas rigidity which probably predominates (Fig. 12). In position 2 the field is turned towards both sides and is limited by $E=2 \pi \sigma_{\mathrm{m}}$, (Fig. 13) it is the law of the Paschen curves which predominates ( $c$ is 7.5 times less, and $\alpha$ has probably 


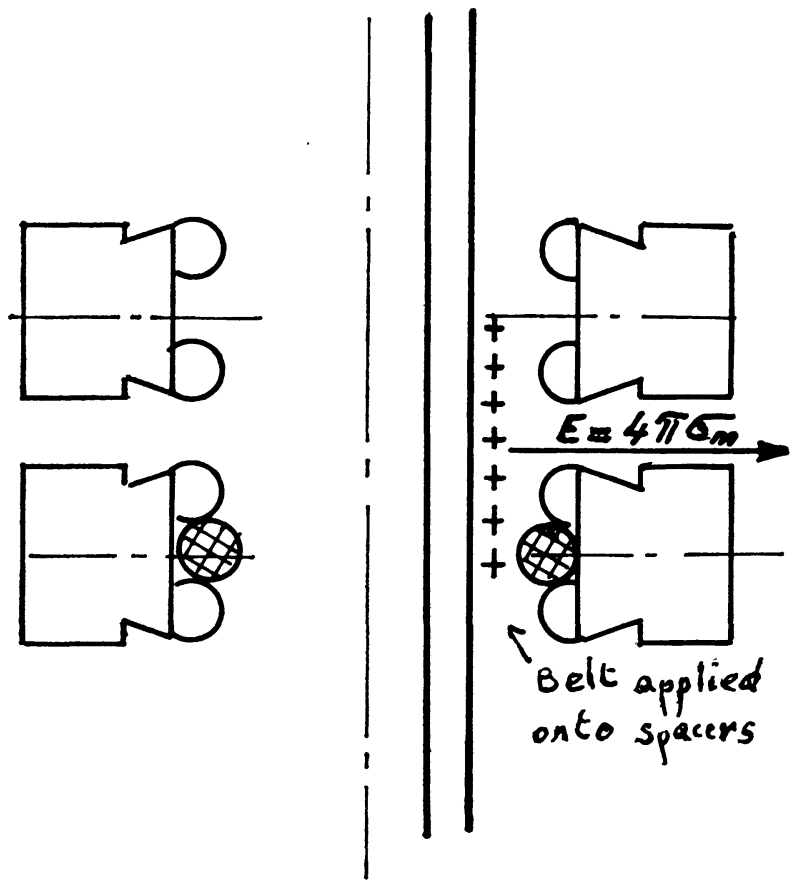

FIG. 12. - Belt field where belt is applied on the spacers.

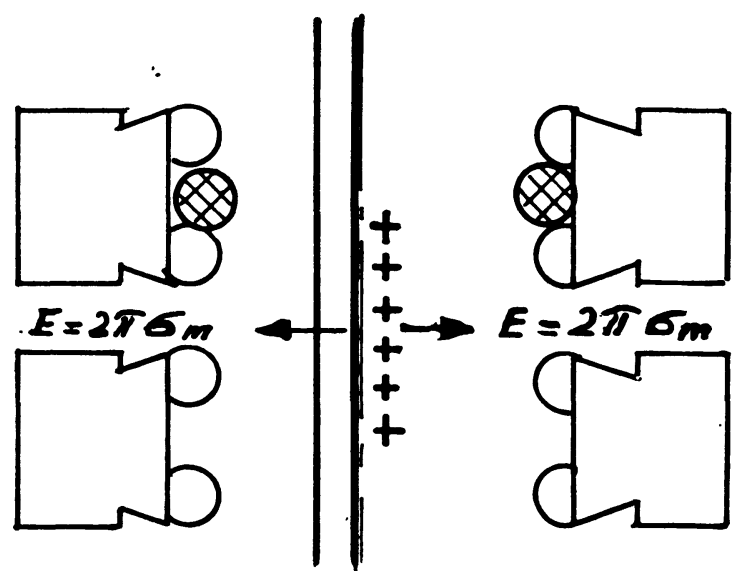

FIG. 13. - Belt field where belt is between the spacer gap.

only slightly changed). It is important to understand this concept of belt capability in its own environment and the corresponding voltage compared to the Paschen curve. This concept, of charge limit density, governs, to my mind, the holding of the charges and it is not only the gas pressure rigidity in a certain field configuration. Discharge occurs to partially neutralize the charges in order to bring the belt voltage under the Paschen limit and then it ceases.

Van de Graaff and Trump developped gradient control rods, to control very high potentials developed transversely across the belt width by the charge on the belt and the varying distance of this charge to the hoops, for example. But bringing the control rods close to the belt, it was this concept of belt charge holding capability which made their machine work.

By the way, the same limitation governs also pelletron or laddertron which cannot carry more in their open SF6 structure that this limit charge, which is in the range, I think, of $3 \mathrm{nC} / \mathrm{cm}^{2}$ in the same condition. Speaking from the charge density point of view and compared to a belt, where the charges are uniformly trapped in belt structure, it is even more critical because of the tangential field, developed by the terminal voltage which pushes the charges back. But there, it is the gas rigidity which is the law and it is O.K. Anyway, they are nice machines for sure and run very well.

In that spacers gap design, I think that there were two bad things, first the geometrical configuration which determines a Paschen curve too inhomogeneous, so too low ( $\alpha$ small) mainly for the positive discharge and, second a structure gap not small enough which allows the belt to run sometimes as in almost an open structure ( $c$ close to the ultime limit), but worst in very bad ambiant conditions.

The consequences of those remarks are very important:

1 - It is impossible to run an M.P. with the present structure as far as we are thinking of charge density close to $4 \mathrm{nC} / \mathrm{cm}^{2}$ that means $400 \mu \mathrm{A}$ on one run and $13 \mathrm{MV}$. Belt spacers and control rods determine a too high inhomogeneous electric field which reduces the belt holding capability. I would say about 320 or $350 \mu \mathrm{A}$ maximum on each run would be safe. Running with more current and depending also on the tangential contribution, i.e. the terminal voltage, will lead, mainly for the belt in the middle position, first to an uniform non disruptive corona discharge onto the belt from one or some of the spacers looking at the belt and second, with increased final belt voltage to a disruptive discharge onto the belt which causes the rapid well known M.P. belt deterioration. I must point out that in Strasbourg, our first belt which ran 22000 hours, entered the spacer gap at the bottom of the spacer gap when leaving the drive motor. Then for some reason, the drive motor and alternator had been risen of 1 or $2 \mathrm{~cm}$ and this new setting compelled the belt to enter the top of the spacer gap and reach the bottom of the spacer gap around dead section 6-7, so the middle position 1 was a compulsory one. This could be a good explanation for the belt life time change.

2 - Reducing the structure gap will probably solve that problem, voltages developped on $d_{2}$ and other spacers have, perhaps, not to be so considered (Fig. 5), but still theoretically it is not probably a good solution because of the high disturbance in belt voltage and the probable too low Paschen curve. But in general to carry more current a smaller structure gap, using properly shaped spacers, must be used in order to increase the belt capability and a gap of the order of $1 \mathrm{~cm}$ would be fine.

By the way, the gap on the $3 \mathrm{MV}$ and the $4 \mathrm{MV}$ machines are in the order of $10 \mathrm{~mm}$, and of $12 \mathrm{~mm}$ with the $\mathrm{CN}$ machine upgraded to $7 \mathrm{MV}$. It is interesting to know that, upgrading this machine was difficult 
and that it was solved pragmatically without explanations. Reducing this gap from $50 \mathrm{~mm}$ for a normal $5.5 \mathrm{CN}$, down to $12 \mathrm{~mm}$ was the only solution that enabled an increase in voltage.

3 - We have already run our machines as in an open structure and we know that they run well at least for the voltage. Either the standard H.V.E.C. structure or, without the internal guides and control rods, what we called the half open structure, should be considered as open structures and finally are the same. Both are bad, from the density point of view because of the inhomogeneous field induced and the voltages developed on the belt relative to the spacers environment. Strasbourg, Brookhaven and Rochester have run with their internal structure removed, that is still and already a test for an open structure. Now I would recommend, to run our M.P. machine, with or without rollers, but with the spacers and control rods far from the belt about something like $5 \mathrm{~cm}$. This spacer is really not a recommendable device, it has to be replaced through one which has a more traditionnal electrostatic good looking, round shape, with ceramic at the top. Keeping the outside guides would prevent harm from column sparking. By the way, it is easy to change a belt in such a configuration, and there will be no more gliding and little dust.

Based on calculation and experiments I personnally think that we can run in that new structure close to $400 \mu \mathrm{A}$ on each run that means close to $800 \mu \mathrm{A}$ for two runs, mainly if we balance the up charge and the down charge currents, may be less on the down charge one.

Electrostatic forces can be very strong. Calculations show that belt charge density of $4 \mathrm{nC} / \mathrm{cm}^{2}$, say an electric field of $46 \mathrm{kV} / \mathrm{cm}$ turned towards one side only (Fig. 12), that means close to one metallic side, pulls the belt with a force of $0.95 \mathrm{~g} / \mathrm{cm}^{2}$. The belt weight is $0.39 \mathrm{~g} / \mathrm{cm}^{2}$. So in case of an horizontal belt in a closed structure, the belt travels mainly stuck on one side and there is as much gliding forces, so dust, as corresponding to the difference or rather the sum of the two values. These gliding forces have to be taken into account by the drive motor. It is interesting to know that the belt weight of $0.39 \mathrm{~g} / \mathrm{cm}^{2}$ is balanced, for an electric field in the proper direction, by a belt density of $2.6 \mathrm{nC} / \mathrm{cm}^{2}$. If we keep in mind that the belt can move in the spacer gap with an electric field, looking towards two directions and with intensities balancing from one side to the other (Fig. 13), these forces can be considered as part of some of the mechanical belt vibration modes and their consequences on the ripple, mainly with a vertical belt. In that case, why not reduce the spacer gap to the order of the belt thickness?

In half open structure, the belt is some $\mathrm{cm}$ from any metallic environment and has an electric field looking on both sides (Fig. 14b) and there is no reason for the belt to be strongly pulled towards any particular direction. For a belt spacer distance of
$5 \mathrm{~cm}$, interaction forces between the two runs of equal but opposite charge polarity are low enough to run. In fact, for $250 \mu \mathrm{A}$ on each run in the M.P. configuration, electric forces are turned to pull the
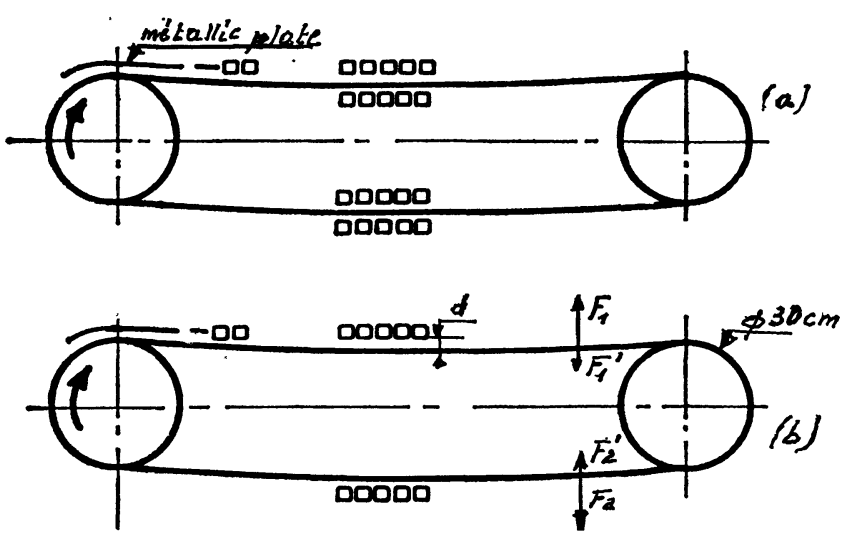

FIG. 14. - Drive motor configuration a) closed structure b) half open structure.

belt outside with a value of $0.095 \mathrm{~g} / \mathrm{cm}^{2}, 10$ times less than in the previous case of closed structure with $400 \mu \mathrm{A}$. And for $400 \mu \mathrm{A}$ on each run the value is $0.24 \mathrm{~g} / \mathrm{cm}^{2}$. So it is always less than the belt weight of $0.39 \mathrm{~g} / \mathrm{cm}^{2}$. It is not the case, if, in that configuration, we run with only the upcharge run, electric forces is $0.54 \mathrm{~g} / \mathrm{cm}^{2}$ so more that the belt weight which allows only $340 \mu \mathrm{A}$ to balance it. May be, rollers in dead sections 'can be useful there. By the way, let me point out that in the case of equal up and down charges, $15 \mathrm{~cm}$ is the theoretical M.P. belt spacer distance where these transverse forces are in equilibrium for any amount of charges, as if the belt runs without charges.

As these forces like the charges are localized only on one belt top surface layer, considerations can be made about the mechanical stress for a very high charge density, and the opportunity for the electric field to look mainly through the belt thickness in some special case.

4 - Where the charged belt leaves the drive motor, the same critical thing happens (Fig. 14). The electric field is, may be, more uniform but still critical. It is certainly not homogeneous around the grooves which, by the way, are not too good from the electric point of view. There is a small plate before entering the column but the problem is on the drive motor. When the charged belt leaves the pulley, with the decrease of the belt capacity, belt voltage is going up rapidly and discharges can occur and negative charges can flash back on to the internal belt side. That is probably the explanation of the experiment carried out in nov. 1976 (Fig. 15) and that, for long, I could not clearly understand. In a half open structure, two terminal metallic insulated rollers are connected together at floating potential, just under 


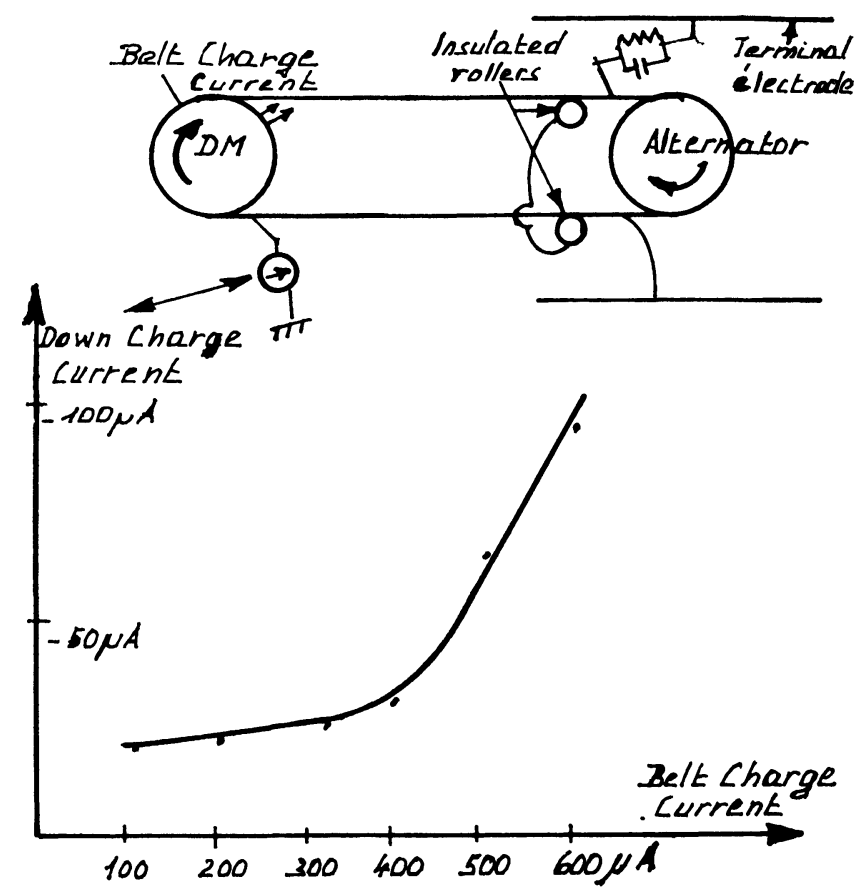

FIG. 15. - Down charge current versus belt charge current with two insulated rollers. French connection.

each belt run. We can see that from $400 \mu \mathrm{A}$ there is a big down charge current increase. That comes probably from negative charges, flashing back from the drive motor when the belt leaves, onto the internal belt side. And those charges, or, at least, part of them, go from the upper roller through the connection to the lower roller onto the external belt side, and down the belt, with the down charge current. So it is essential to put a grounded plate, fixed on the drive motor to allow the drum to be pulled, and with a gap distance which can be never more than $10 \mathrm{~mm}$ even in belt flapping condition. So it is better to be less, say $7 \mathrm{~mm}$ and which requires some guidance either spacer or intermediate roller because of the overshoot, this run not being stretched. Two metallic plates, one on each belt side can be put at a slightly higher distance to balance the electric pulls and avoid the gliding mainly in case of high charge density.

5 - The same philosophy must bring some care about charge removal area in the terminal electrode. When the charged belt enters a conductor free space, discharges must not occur before proper removal. A proper location of the charge eliminator screen must be found in order to have a good efficiency including removal of parasitic charges. In addition of some grounded plates, there is a problem about the charge density, if below $4 \mathrm{nC} / \mathrm{cm}^{2}$, or if above $4 \mathrm{nC} / \mathrm{cm}^{2}$ where two discharging steps can be considered as the so called french connection screen, otherwise either discharge can occur in a wrong place or the eliminator screen does not act properly [1].

In conclusion, are the belt charging systems to be given up ? We think that belt is a simple and well adapted conveyor for carrying charges in a tangential field and possibly a lot of charges because of its polymer structure. Belt manufacturers must deliver the same quality of belt as previously. But with that ground, we think we probably now understand what happens, even with the parasite charges and how to better control them. In fact, not many things have been done on belt with a clear concept of what was going on. And it appears now that the main problem was the M.P. belt deterioration due, to my mind, to a fundamental physical process resulting from the combination of tangential structure voltage and normal belt voltage, which process can only lead to a high electric strain and consequently to a belt deterioration. With some care, this problem which exists for any kind of machine can be solved easily for a M.P. For the voltage ripple, attacking this problem with the same philosophy as with a pelletron to control essentially the high voltage modulation with the belt charge voltage itself, simple solutions can be applied. Then it seems that, belt has not only the past behind it, but with some technical effort, can also be considered for some part of the future.

References

[1] Letournel M., Oberlin J. C., Revue Phys. Appl. 12 (1977).

[2] BerTein H., Elektrostatische Aufladung (Dechema), 183, 1973. 